Hotchin, J. E. (1954). J. gen. Microbiol. 10, 250-260.

\title{
The Purification and Electron Microscopical Examination of the Structure of Staphylococcal Bacteriophage K
}

\author{
By J. E. HOTCHIN \\ The National Institute for Medical Research, The Ridgeway, \\ Mill Hill, London, N.W. 7
}

SUMMARY: Staphylococeal bacteriophage $\mathbf{K}$ was concentrated and purified from broth lysates without the use of high-speed centrifugation, which inactivates this phage. After precipitation with $30 \%(\mathrm{v} / \mathrm{v})$ acetone in water in the cold, the phage was further purified by treatment with isobutanol and chloroform, and concentrated by pressure filtration in reinforced collodion sacs. Electron microscopical examination revealed the presence of empty phage heads and tails, in addition to intact phage in the purified concentrate. Experiments indicate that while these entities could be made by disintegration of the phage, they were already present in this form in the original lysate. Study of the structure of the phage indicates the presence of a removable solid rod or plug within the tail which terminates in the terminal bob. These findings are discussed in relation to the structure of other phages, and their physiology.

During attempts to concentrate and purify the staphylococcal phage $\mathbf{K}$, the appearance of the product was frequently examined by electron microscopy; particles were seen which appeared to be 'pieces' of the phage. This phage is a tailed variety and the pieces seen appeared to correspond to individual structures, such as loose tails, of which the intact phage was composed. A method of purification was devised which did not result in the fractionation of these structures until the final stage, while still permitting the concentration of the phage and removal of contaminating particulate debris of about the same size as the phage. This method is described below with the results of electron microscopical examination of the products.

\section{METHODS}

Organism. The organism used throughout was the Oxford strain of Staphylococcus aureus, NCTC 6571. The phage used was staphylococcal bacteriophage K. Hartley tryptic digest broth was used as nutrient medium throughout.

Bacteriophage assay. This was made by plaque counts on the surface of $1 \%$ nutrient agar plates.

Electron microscopy. Examinations were made with a Siemens electron microscope. Each specimen was prepared at several dilutions in distilled water containing $\mathbf{0 . 0 5} \%$ osmic acid; a drop of each dilution was placed on a collodion covered mounting grid and allowed to dry over phosphorus pentoxide. The material was shadow cast before being photographed in the microscope: gold-manganin approx. $6 \mathrm{~A}$. thick at an angle of $15^{\circ}$ was used for shadowing.

The assessment of the efficiency of the purification procedures used. Since the bacteriophage was being prepared mainly for electron microscopical study, examination of the product by this method was made at each stage of the 
purification process. In addition, chemical estimations were made of the nitrogen and in some cases the phosphorus content of the preparation. As a result of this, the opinion was formed that an electron micrograph made by the technique described gave excellent qualitative information on the purity of the product. The dried material used for microscopy contained all the constituents present in the preparation; thus, crystalline or amorphous deposits from dissolved impurities and particulate matter were readily seen. Small quantities of other dissolved impurities, such as proteins, caused a diminution in sharpness of the outlines of phage particles, while larger amounts completely obliterated them. It was found that chemical estimations frequently gave less useful information than electron microscopical examination; consequently more importance was attached to the latter method. This was particularly true for procedures designed to remove particulate material of the same order of size as the bacteriophage.

The production of bacteriophage. Cultures were grown either in $4 \mathrm{l}$. bottles (containing 11 . of broth) aerated by mechanical shaking, or in larger vessels aerated by air forced through a porcelain filter candle which was immersed at the bottom of the medium; the porosity of the candle was not critical. Foaming was controlled by small quantities of tributyl citrate or silicone antifoam. The ratio of initial phage particles added to the number of bacterial cells present was found to be unimportant so long as sufficient phage was added during the growth of the host cells to cause lysis to be complete shortly before growth ceased in a control culture without phage. A typical infective ratio used was an initial concentration of approximately $10^{6}$ phage particles and $3 \times 10^{8}$ viable cells $/ \mathrm{ml}$. (determined by colony counts). Such a system gave complete lysis in 3-4 hr. and contained $1-2 \times 10^{10}$ plaque-forming units/ml.

The concentration of bacteriophage. Centrifugation in the Sharples centrifuge was found to cause inactivation of this phage. Other methods of concentration tried included adsorption, elution, vacuum distillation, enzymatic digestion, precipitation and pressure filtration. The last two of these were found to be the most useful. Several reagents, including acetone, methanol and ethanol, and ammonium sulphate were used as precipitating agents. Preliminary tests indicated that the phage was most stable to acetone and this was chosen for more detailed study, the results of which are shown in Table 1 . It was evident that the phage was able to withstand acetone precipitation for $18 \mathrm{hr}$. at $0^{\circ}$. Thirty to thirty-five $\%(\mathrm{v} / \mathrm{v})$ acetone in water was used to concentrate the phage in larger volumes of lysate. By using acetone at $-10^{\circ}$ and the lysate at $0^{\circ}$, from 50 to $100 \%$ of the viable phage was recoverable in an aqueous solution of the precipitate. This solution was turbid and contained from one-tenth to one-twentieth of the nitrogen originally present in the lysate. In view of the surprising stability of this bacteriophage to dilution in pure acetone (see Table 1), an attempt was made to find a two-phase system, in which the bacteriophage might partition in a constant manner, enabling a purification to be effected by either a countercurrent technique (Craig, 1949) or by partition chromatography on some supporting column. Such 
systems have been developed by Martin \& Porter (1951) with remarkable results for the separation of enzymes. However, no system was found in which the bacteriophage would partition between both phases.

Table 1. The stability of staphylococcal phage $K$ to acetone at $0^{\circ}$ for $18 \mathrm{hr}$.

All tubes were centrifuged at $18 \mathrm{hr}$, and the pellets resuspended in $10 \mathrm{ml}$. broth for titration. Cold acetone was added to the cold mixture of $0.1 \mathrm{ml}$. of diluted phage, and broth.

$\begin{array}{ccccccc}\text { Tube no. } & \begin{array}{c}\text { Broth } \\ (\text { ml. })\end{array} & \begin{array}{c}\text { Acetone } \\ \text { (ml.) }\end{array} & \begin{array}{c}\text { 1st expt., } \\ \text { plaque count } \\ \text { of supernatant }\end{array} & \begin{array}{c}\text { Plaque count } \\ \text { of pellets }\end{array} & \begin{array}{c}\text { 2nd expt., } \\ \text { plaque count supernatant }\end{array} & \begin{array}{c}\text { Plaque count } \\ \text { of pellets }\end{array} \\ \mathbf{1} & 10 & - & \mathbf{8} & 1 & 8000+ & 75 \\ 2 & 9 & 1 & 19 & 1 & 8000+ & 80 \\ 3 & \mathbf{8} & 2 & 16 & 2 & 8000+ & 378 \\ 4 & 7 & 3 & 7 & 5 & 800 & 8000 \\ 5 & 6 & 4 & 1 & 6 & 92 & 6000 \\ 6 & 5 & 5 & 1 & 11 & 92 & 4000 \\ 7 & 4 & 6 & 1 & 4 & 60 & 5000 \\ 8 & 3 & 7 & - & 4 & 37 & 3000 \\ 9 & 2 & 8 & - & 6 & 11 & 3000 \\ 10 & 1 & 9 & - & 2 & - & 23 \\ 11 & - & 10 & 4 & - & 2500 & 10\end{array}$

During tests with isobutanol, and to a lesser extent with chloroform, it was noticed that a very stable emulsion was frequently formed on shaking the solvents with aqueous suspensions of the acetone precipitate of phage lysates. When the system was centrifuged at low speed, the two phases were separated, with debris and a small amount of emulsion remaining at the liquid/liquid interface. The preparation which had been originally white and opaque was now quite translucent, and showed a strong bluish opalescence; titrations of the aqueous phase showed it to contain $90 \%$ or more of the original phage. The change in nitrogen content of the preparation as a result of this treatment was measured and found to be about halved; it seemed likely that bacterial debris was being retained in the emulsion; this was confirmed by electron microscopy (see below). In one experiment, treatment with isobutanol and chloroform reduced the optical density (using a tungsten lamp without a filter) of the preparation from 0.63 to 0.11 without change in titre.

Treatment of the acetone precipitate of a phage lysate in this manner with isobutanol was considered to be of great value in removing from the phage preparation particulate material which was very difficult to separate by other methods. Under optimal conditions about $95 \%$ recovery of bacteriophage could be obtained without washing the organic phase emulsion for residual phage; the only suspending medium for the phage, which gave this recovery, was distilled water. Broth suspensions lost up to $90 \%$ of their phage content; saline and buffer solutions gave intermediate values. The bacteriophage was progressively inactivated in water, losing about $90 \%$ of activity at $0^{\circ}$ in 1 week. Therefore, it was only kept in aqueous suspension for a few hours. In practice, an isobutanol+chloroform mixture is more convenient to use than isobutanol alone. Chloroform kills bacterial contaminants of the suspension, and the density of a 50/50 mixture of these solvents is greater than that of water, thus facilitating removal of the upper aqueous phase after 
centrifugation. Maximal yields of bacteriophage were only obtained with phage titres below $10^{11} / \mathrm{ml}$; higher concentrations gave progressively lower yields.

Concentration of the aqueous bacteriophage suspensions. After the above treatments, the resulting suspension of phage was still relatively dilute and contained dissolved impurities. A simple method of concentration was found to be pressure filtration at $0^{\circ}$ through reinforced collodion sacs prepared by a method developed by van den Ende, Don, Elford, Challice, Dawson \& Hotchin (1952). Sacs prepared in this way withstand a pressure of $20 \mathrm{lb}$./sq.in., which is sufficient to concentrate about $500 \mathrm{ml}$. of phage suspension $/ \mathrm{sac} / \mathbf{2 4} \mathrm{hr}$., using a reservoir of the dilute phage suspension fed under pressure into the sac. In this process a variable amount of soluble impurity is lost, depending on the porosity of the sac. The recovery, when using this concentration method performed in the cold, was very good, 80-95\% of infectivity being regularly obtained. Final purification of the bacteriophage concentrate to remove remaining soluble material was obtained by centrifugation at about $10,000 \mathrm{~g}$.

The purification procedure finally adopted can be summarized as follows. The crude lysate was collected as soon as lysis was complete and stored overnight at $0^{\circ}$. Acetone at $-10^{\circ}$ to $-15^{\circ}$ was added at $0^{\circ}$ with stirring to give a final concentration of $30 \%(\mathrm{v} / \mathrm{v})$. When precipitation was not obvious, the concentration of acetone was increased to $35 \%$. After standing for $2 \mathrm{hr}$. at $\mathbf{0}^{\circ}$ the precipitate settled and the clear supernatant was poured off. The lower layer was centrifuged at $0^{\circ}$ for $5 \mathrm{~min}$. at low speed to sediment the precipitate. The latter was dissolved in distilled water to give a final concentration of about $5 \times 10^{10}$ phage particles $/ \mathrm{ml}$. and shaken for $5 \mathrm{~min}$. at $0^{\circ}$ with half its volume of a mixture of equal parts of $i$ sobutanol and chloroform. The resulting emulsion was centrifuged at low speed to separate the two phases, the upper aqueous one (containing the phage) then being removed. The isobutanol + chloroform treatment was repeated twice. The aqueous suspension was then concentrated by pressure filtration through collodion sacs to a few $\mathrm{ml}$. The preparation at this stage (concentrate) was found to contain the formed elements described in the next section and also a variable amount of protein and other impurities in solution. The phage could be removed and washed by centrifugation at about $10,000 \mathrm{~g}$ without loss of activity; final suspension was made in saline or in water for electron microscopy. Details of the yields obtained in this purification procedure are given in Table 2. The purified phage had a nitrogen content of $7 \times 10^{-16} \mathrm{~g} \cdot /$ plaque-forming unit. The nitrogen : phosphorus ratio was 5.0 g. $/ \mathrm{g}$.

\section{Table 2. Yield of plaque-forming units obtained during purification}

Stage of purification

Acetone precipitation

isoButanol+chloroform treatment

Pressure filtration

Centrifugation at $10,000 \mathrm{~g}$

Washing and recentrifugation

Overall yield
Yield as \% of

previous stage

50-100

85-95

80-95

80-90

70-90

19-73 


\section{RESULTS OF ELECTRON MICROSCOPICAL EXAMINATIONS}

The bacteriophage concentrate obtained as described above was found to contain what appeared in electron micrographs to be intact phage particles, loose phage tails and empty heads without tails. After centrifugation at 10,000 r.p.m. for 2 hr. in an Ecco centrifuge with swing-out buckets, three layers were visible in the preparation. These consisted of a slightly opalescent supernatant or top layer, a very opalescent middle layer, and a translucent amber pellet. Samples of each of these layers were removed and examined electron microscopically. The bottom layer, or pellet (Pl. 1, fig. 1), consisted almost entirely of intact phage particles; the middle layer (PI. 1, fig. 2) consisted largely of what appeared to be empty phage head membranes. The top layer (Pl. 1, fig. 3) contained some of the structures seen in the middle layer and, in addition, what appeared to be separate tails. Pl. 1, fig. 4, shows the state of the preparation before the isobutanol treatment. The phage is seen to be contaminated by the presence of circular 'foamy' bodies, an intact staphylococcus, some small particles, and amorphous debris. There are present some free head membranes as described above and a few tails. The decrease in turbidity observed after treatment of this stage with isobutanol is apparently due to the removal of the 'foamy' structures and remaining unlysed organisms seen in Pl. 1, fig. 4.

The origin of separate phage head membranes and tails. It was thought at first that if the structures described in Pl. 1, figs. 2 and 3 , are in fact head membranes and tails, they might have been produced by the purification procedure. However, this is shown not to be the case by the following facts: (i) similar structures are seen in Pl. 1, fig. 4, before isobutanol treatment; (ii) repeated isobutanol treatment of the pure phage (as shown in Pl. 1, fig. 1) neither significantly altered its plaque-forming titre, nor produced an appreciable number of head membranes or tails in subsequent electron micrographs; (iii) electron microscopy of the original lysate prepared by adsorbing the lysate constituents on to the collodion membrane (pictures were too dense when prepared by the standard procedure) showed the presence of head membranes and tails; (iv) similar structures have been described by other workers (see Discussion) in preparations of this and other phages prepared by different techniques.

The production of head membranes and tails from intact phage. In order to demonstrate that the head membranes and tails were the same as corresponding structures in the intact phage particle, an attempt was made to break down the purified phage into free tails and empty head membranes, plus the contents of the heads. Such a breakdown was achieved by shaking $5 \mathrm{ml}$. of a suspension of the purified phage preparation (containing about $5 \times 10^{10}$ plaque-forming units/ml.) for $2 \mathrm{hr}$. in a Mickle (1948) disintegrator without the addition of any abrasive; under these conditions the titre fell by a factor of about 100. Plate 1, fig. 5, shows an electron micrograph of the purified bacteriophage (seen in Pl. 1, fig. 1) after $\mathbf{2} \mathrm{hr}$. shaking in the Mickle disintegrator. It can be seen that very little normal phage remains; free phage tails are present, 
and free empty head membranes, many of which are clumped together. In addition, there is some fibrillar material and a few small particles. Several of the tails appear to show evidence of internal structure; this will be discussed later. After disintegration by shaking, the phage preparation was centrifuged under the same conditions as those required to separate the whole phage, head membranes, and tails into three layers, as described above. The total amount of material used was small, and the preparation after centrifugation could only be divided into a small pellet and a clear supernatant. Pl. 2, fig. 6, shows an electron micrograph of the pellet, and Pl. 2, fig. 7, shows the supernatant. It can be seen that the appearance and behaviour of the structures obtained by disintegration of the phage are very similar to the head membranes and tails extracted from the lysates. It was concluded that they are essentially the same.

The appearance of osmotically shocked $\boldsymbol{K}$ bacteriophage. A portion of the purified bacteriophage (the 'bottom-pellet' of the phage concentrate) was subjected to osmotic shock as described by Herriott (1951). Its titre fell by a factor of about 1000. The appearance of the preparation following shocking is seen in Pl. 2, fig. 8; empty head membranes are seen, also free tails and some complete phage units with empty heads. There is a large amount of fibrillar substance which is dotted with small particles, with diameters somewhat less than that of the phage tail. This preparation was deproteinized by shaking with a mixture of octyl alcohol and chloroform and was examined spectrophotometrically. A nucleic acid type of absorption spectrum was obtained with a minimum at $2370 \mathrm{~A}$. and a maximum at $2560 \mathrm{~A}$.

\section{Conclusions as to the structure of the $K$ bacteriophage}

During the examination of many electron micrographs obtained during the experiments described above, particularly in the photographs of disintegrated phage, many examples were obtained which appeared to show more structural detail than has been described for this or any other phage. The $\mathbf{K}$ bacteriophage was described by Smiles, Welch \& Elford (1948) as consisting of a spherical head and a relatively long tail which terminated in a round ' bob'. This description is confirmed by the present study; in addition, evidence is presented which indicates that the tail of this phage consists of a hollow cylindrical sheath, containing a central solid rod, which terminates in the tail bob at one end and inside the nucleic acid-containing head at the other. Examples of photographs suggesting this are shown in Pl. 1, fig. 5, and Pl. 2, fig. 7. Countless other examples have been found, some of the most typical of which are shown in Pl. 2, figs. 9-14; figs. 9-13 are from Mickle disintegrated phage and the remainder from various batches of partially purified phage. Pl. 2, fig. 9, shows an intact free tail; in fig. 10 can be seen two tails, each of which is composed of a thick and thin half; in fig. 11 can be seen other examples of a constriction or narrowing of the tail, and in fig. 12 the tail is separated from the head by a 'neck' consisting of a narrow rod or thread. Pl. 2, figs. 13 (top) and 14, show examples of what is considered to be the terminal bob of the tail, attached to a relatively thin rod which has become detached from the tail of 
a phage particle. The size of the rod fits the assumption that it is the same structure as seen projecting from portions of tails in other pictures, and that it is the normal internal core of the phage tail. The structure of the phage, as indicated by these experiments, is indicated diagrammatically in Fig. 1. Preliminary chemical analysis indicates that the head membrane and tail are composed of protein with little, if any, phosphorus present; no detailed analysis of the composition of these structures has been made.

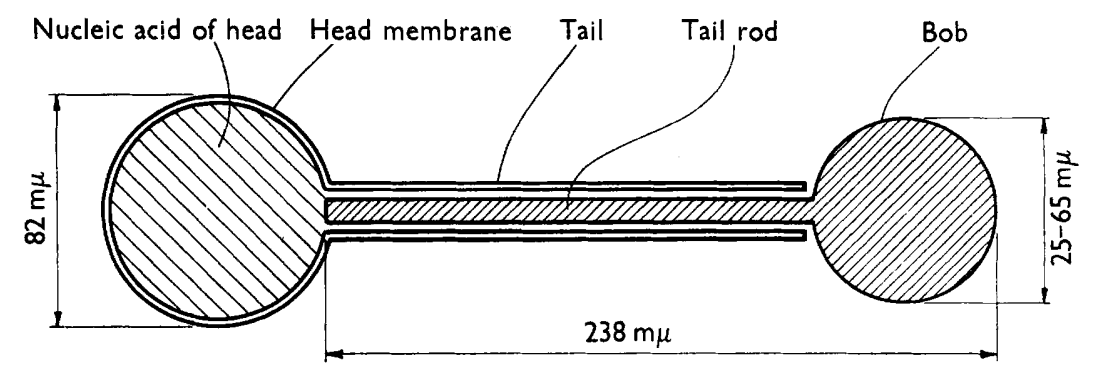

Fig. 1. Diagram showing the possible structure of staphylococcal bacteriophage $\mathrm{K}$ as indicated by electron microscopy.

\section{DISCUSSION}

Many different techniques have been used in the past to purify and concentrate bacteriophage. Clifton (1930) used adsorption on to alumina to purify staphylococcal phage, and this method has been expanded by Wahl et al. $(1939,1950)$ and others. Concentration on collodion membranes was used by Elford (1938) and by Hershey, Kalmanson \& Bronfenbrenner (1943), and concentration on foam was used by Bloch (1940). Northrop (1938) used several original methods in a study of the concentration and purification of a staphylococcal phage; his methods included low temperature distillation in vacuo, digestion with crystalline trypsin, and ammonium sulphate and lead acetate precipitation of the bacteriophage. Organic solvents have been tried as precipitating agents by Bronfenbrenner \& Korb (1925) and by Wahl \& Blum-Emerique (1949) who obtained good results with ethanol. Acetone was tested by Colwell (1937) and found to inactivate coli phage, but this agent did not destroy staphylococcal phage $\mathbf{K}$ at low concentrations in experiments performed by the late W.J. Elford (personal communication). Most of the above methods were tested for applicability to the concentration and purification of staphylococcal phage $\mathbf{K}$ in the course of the work described in this paper.

The purification method finally adopted and described here represents the most efficient procedure of those tested for this phage, obtained in a particular way. It is of some interest to compare the values for the nitrogen content of the phage with those of Northrop (1938), who worked with a staphylococcal phage, and found a sevenfold lower nitrogen content for his phage $\left(1 \times 10^{-16} \mathrm{~g}\right.$. $\mathrm{N} /$ infective unit) than that found in the present work. Whether or not the two phages are identical is not known, nor is the proportion of viable $\mathbf{K}$ phage particles in the preparation; estimations of the opalescence of some of the 
pure preparations of identical titre indicate that this was very variable, and sometimes quite low. This variability seemed to be related to the proportion of viable phage particles due to changes in the conditions of bacteriophage production, rather than purification; it was not investigated further.

A method of virus purification which largely avoids high-speed centrifugation has several merits. It is very suitable for working with large volumes of material; it may be useful for small viruses less easily concentrated by centrifugation and is essential if the virus is inactivated by the usual methods of high-speed centrifugation. The finding that staphylococcal phage $\mathbf{K}$ is susceptible to high centrifugal stress confirms a report by Wyckoff (1938). A method of purification of $\mathrm{T}_{2}$ bacteriophage similar to the present one has recently been devised by Herriott \& Barlow (1952); these workers concentrated and purified the bacteriophage by precipitation at a lowered $\mathrm{pH}$.

From the study described here, it is evident that centrifugal methods of purification of staphylococcal bacteriophage $K$ result in removal from the final product of the head membranes and free tails described. It is possible that similar structures to those described here will be found for other phages if methods of concentration are used which do not exclude them. There is evidence (see below) that this is so for $T_{2}$ phage when purified by the method of Herriott \& Barlow. The treatment with isobutanol and chloroform, although arrived at in quite a different way, appears to operate in an analogous manner to the deproteinization of solutions by shaking with chloroform described by Sevag (1934). In both cases, the impurity collects and is removed at the interfacial surface between the organic and aqueous phases. The bacteriophage is presumably protected from surface inactivation by the slight excess of protein remaining in solution during the treatment; the substitution of octyl alcohol (commonly added to chloroform as an anti-foam agent) for isobutanol caused a marked loss of bacteriophage. The 'foamy structures' removed by isobutanol and chloroform treatment are thought to be remnants of the cell membranes of lysed cells. The stability of the phage in almost $100 \%$ acetone (Table 1) seemed most remarkable. Although this observation led to the use of other organic solvents, no other practical use has so far been made of it.

The value of electron microscopical examination in assessing the purity of phage preparations may be stressed. Ideally, quantitative electron microscopy as described by Williams \& Backus (1949) and by Backus \& Williams (1950) is required before chemical analysis can be equated with the number of phage particles. The plaque count will then show the proportion of these which are viable.

Preparations of bacteriophage containing empty head membranes and tails were reported by Smiles et al. (1948) and by van den Ende et al. (1952). Heden (1951) and Herriott \& Barlow (1952) reported small 'phage-like' bodies in $\mathrm{T}_{2} r+$ lysates. These bodies have a small head and a thinner tail than the $\mathrm{T}_{2}$ phage, but are about the same length as the tail. They appear to be associated with infection by the $\mathrm{T}_{2} r+$ phage, and may correspond to the 'rod and bob' unit described in this paper and shown in Pl. 2, figs. 13 and 14. 
The results of Kellenberger \& Kellenberger (1952) are of extreme interest in connexion with the rod units reported here. These workers published electron micrographs of a most unusual group of bacteriophages obtained by ultraviolet-induced lysis of Bacillus cereus. Photographs of some of these phages show the head of the phage to be separated from the tail by a 'neck', and are strikingly similar in appearance to Pl. 2, fig. 12. Other variations are shown, closely resembling those described in this paper. It appears that one of the B. cereus phages normally has near the head a portion of its tail constricted as a 'neck'; the authors considered that some of the other forms they found were derived from this. There is apparently some indication that the tail structure described here may be of general occurrence among bacteriophages.

The pitfalls of a too ready acceptance of electron microscopic appearances are becoming well known. If it be accepted that the phage tail, at least in some cases, contains an inner rod-like core which is readily separable from its outer sheath, it is tempting to speculate as to its function. Herchey \& Chase's results (1952) on the deoxyribosenucleic acid injecting action of the $\mathbf{T}_{2}$ bacteriophage have revolutionized the conception of phage infection. In Hershey's results only about $\mathbf{8 0} \%$ of the phage protein is accounted for outside the host after infection. This leaves room for the speculation that the inner core or rod of the tail may enter the bacterium before the nucleic acid. If this should be so, it is not inconceivable that this part of the tail may be responsible for the inhibition of host cell function. This property has been shown by Herriott (1951) to reside in nucleic acid-free osmotically shocked 'ghosts' of $\mathbf{T}_{\mathbf{2}}$ phage. The significance of the small spherical particles seen in several of the present photographs, especially Pl. 2, figs. 7 and 8, is not known. It is felt that these may be artifacts due to fixation or drying, as their presence and appearance has been very variable. However, they may be present as particles within the phage head, and the appearance of the phage head in Pl. 1, fig. 1, does suggest this, although this again may be an artifact due to the drying technique used.

I wish to acknowledge the excellent technical assistance of Mr D. V. Law and Mrs I. M. Honey who made most of the electron micrographs.

\section{REFERENCES}

Backus, R. C. \& Williams, R. C. (1950). The use of spraying methods and volatile suspending media in the preparation of specimens for electron microscopy. J. appl. Physiol. 21, 11.

Bloch, H. (1940). Über einen Potenzierungseffekt bei Bakteriophagen. Arch. ges. Virusforsch. 1, 560.

Bronfenbrenner, J. J. \& Korb, C. (1925). Studies on the bacteriophage of D'Herelle. II. Effect of alcohol on the bacteriophage of D'Herelle. J. exp. Med. 42, 419.

Cuifton, C. E. (1930). A method for the purification of the bacteriophage. Proc. Soc. exp. Biol., N.Y. 28, 32.

Colweld, C. A. (1937). Purified bacteriophage from lysogenic cultures. Proc. Soc. exp. Biol., N.Y. 36, 100.

Craig, L. H. (1949). Studies on polypeptides and amino acids by countercurrent distribution. Cold Spr. Harb. Sym. quant. Biol. 14, 24. 
Elford, W. J. (1938). The sizes of viruses and bacteriophages and methods for their determination. In Handbuch der Virusforschung, Doerr, R. \& Hallauer, C. ed. pp. 126-76. Vienna: Julius Springer.

Ende, M. van den, Don, P. A., Elford, W. J., Challice, C. E., Dawson, I. M. \& Нотснік, J. E. (1952). The bacteriophages of Pseudomonas aeruginosa filtration measurements and electron microscopy. J. Hyg., Camb. 50, 12.

Hedén, C. G. (1951). Studies of the infection of $E$. coli B with the bacteriophage $T_{2}$. Acta path. microbiol. scand. Suppl. 88.

Herriott, R. M. (1951). Nucleic-acid-free $T_{2}$ virus 'ghosts' with specific biological action. J. Bact. 61, 752.

Herriott, R. M. \& Barlow, J. L. (1952). Preparation, purification and properties of $E$. coli virus $\mathrm{T}_{2}$. J. gen. Physiol. 36, 17.

Hershey, A. D. \& Chase, M. (1952). Independent functions of viral protein and nucleic acid in growth of bacteriophage. J. gen. Physiol. 36, 39.

Hershey, A. D., Kalmanson, G. \& Bronfenbrenner, J. (1943). Quantitative methods in the study of phage-antiphage reaction. J. Immunol. 46, 267.

Kellenberger, G. \& Kellenberger, E. (1952). La lysogénie d'une souche Bacillus cereus. Mise en évidence par le microscope électronique. Schweiz. Z. allg. Path. $15,225$.

Martin, A. J. P. \& Ponter, R. R. (1951). The chromatographic fractionation of ribonuclease. Biochem. J. 49, 215.

Mickle, H. (1948). Tissue disintegrator. J. R. micr. Soc. 68, 10.

Northrop, J. H. (1938). Concentration and purification of bacteriophage. J. gen. Physiol. 21, 335.

Sevag, M. G. (1934). Eine neue physikalische Enteiweissungsmethode zur Darstellung biologisch wirksamer Substanzen. Biochem. Z. 273, 419 .

Smiles, J., Welch, F. V. \& Elford, W. J. (1948). The influence of antibacterial substances on the interaction of bacteria and bacteriophages. II. Optical studies of the penicillin effect. J. gen. Microbiol. 2, 220.

Wahl, R. \& Blum-Emerique, L. (1949). Purification et concentration du bactériophage. II. Précipitation par l'ethanol et redissolution des phages-essais divers. Ann. Inst. Pasteur, 76, 103.

WAHL, R. \& LewI, S. (1939). Étude de l'adsorption du bactériophage (du B. subtilis) sur l'hydrate d'alumine. C.R. Soc. Biol., Paris, 131, 591.

Wahl, R., Terrade, A. \& Monceaux, G. (1950). Préparation des lysats bactériophagiques de titre élevé. Purification et concentration des phages par deux adsorptions successives sur phosphate de calcium. Ann. Inst. Pasteur, 79, 429.

Williams, R. C. \& Backus, R. C. (1949). Macromolecular weights determined by direct particle counting. I. The weight of the bushy stunt virus particle. J. Amer. chem. Soc. 71, 4052.

Wyckoff, R. W. G. (1938). An ultracentrifugal analysis of concentrated staphylococcus bacteriophage preparations. J. gen. Physiol. 21, 367. 


\section{EXPLANATION OF PLATES}

For detailed description of figures, see text.

\section{Plate 1}

Fig. 1. Electron micrograph of staphylococcal bacteriophage $K . \times 67,650$.

Fig. 2. Empty heads of staph. bacteriophage $K . \times 23,250$.

Fig. 3. Tails of staph. bacteriophage $K . \times 48,960$.

Fig. 4. Partially purified phage preparation. $\times 12,240$.

Fig. 5. Purified bacteriophage after treatment in Mickle disintegrator. $\times \mathbf{2 8 , 9 8 0}$.

\section{Plate 2}

Fig. 6. Preparation of head membranes from disintegrated phage. $\times \mathbf{2 5 , 1 3 5}$.

Fig. 7. Preparation of tails from disintegrated phage. $\times \mathbf{3 8 , 4 8 0}$.

Fig. 8. Appearance of staph. phage $K$ after osmotic shock. $\times 36,080$.

Fig. 9. Typical free phage tail. $\times \mathbf{5 2 , 5 8 0}$.

Fig. 10. Phage tails showing details of internal structure. $\times \mathbf{5 2 , 9 1 0}$.

Fig. 11. Phage tails showing constricted portions. $\times 46,970$.

Fig. 12. Phage particle showing the head separated from the tail by a 'neck'. $\times 48,510$.

Fig. 13. Portions of phage tail, including inner rod, or 'plug', and terminal bob. $\times 38,240$.

Fig. 14. Portions of phage tail, including inner rod, or 'plug', and terminal bob. $\times \mathbf{4 6 , 9 7 0}$.

(Received 20 August 1953) 
Journal of General Microbiology, Vol. 10, No. 2

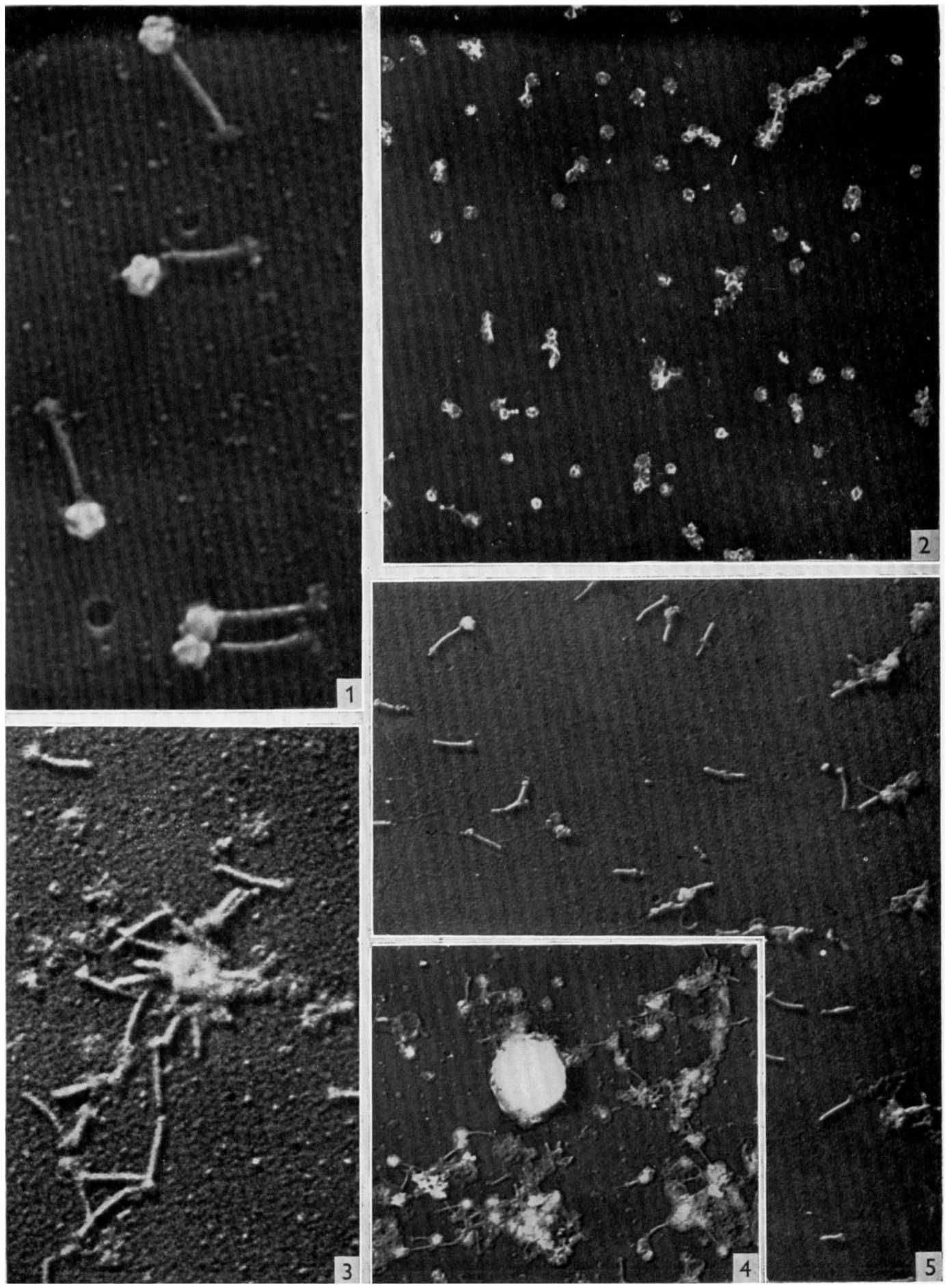

J. E. Hotchin-Staphylococcal bacteriopiage K. Plate 1 
Journal of General Microbiology, Vol. 10. No. 2

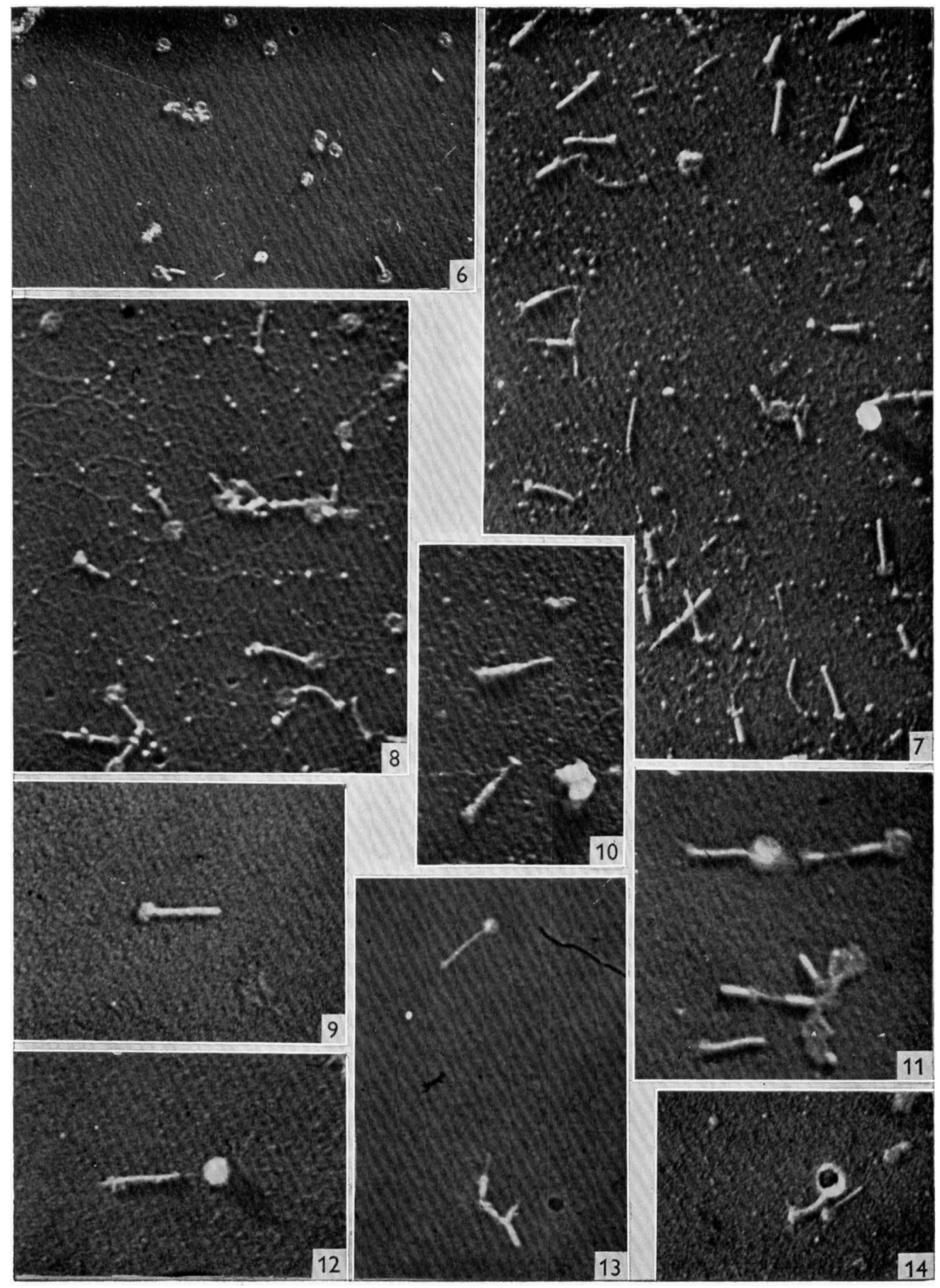

J. E. Hotchin-Staphylococchl bacteriophage K. Plate 2 